\title{
BMJ Open Association between male involvement during antenatal care and use of maternal health services in Mwanza City, Northwestern Tanzania: a cross- sectional study
}

\author{
Clara C Natai, ${ }^{1}$ Neema Gervas, ${ }^{1}$ Frybert M Sikira, ${ }^{1}$ Beatrice J Leyaro (D) , \\ Juma Mfanga, ${ }^{3}$ Mashavu H. Yussuf (D) , ${ }^{1}$ Sia E Msuya ${ }^{2,4}$
}

To cite: Natai CC, Gervas N, Sikira FM, et al. Association between male involvement during antenatal care and use of maternal health services in Mwanza City, Northwestern Tanzania: a crosssectional study. BMJ Open 2020;10:e036211. doi:10.1136/ bmjopen-2019-036211

- Prepublication history for this paper is available online. To view these files, please visit the journal online (http://dx.doi. org/10.1136/bmjopen-2019036211).

Received 06 December 2019

Revised 05 June 2020

Accepted 07 August 2020

Check for updates

(c) Author(s) (or their employer(s)) 2020. Re-use permitted under CC BY-NC. No commercial re-use. See rights and permissions. Published by BMJ.

For numbered affiliations see end of article.

Correspondence to

Dr Mashavu H. Yussuf; mashay55@gmail.com

\section{ABSTRACT}

Background Male involvement in antenatal care (ANC) is among interventions to improve maternal health. Globally male involvement in ANC is low and varies in low-income and middle-income countries including Tanzania where most maternal deaths occur. In Sub-Sahara, men are chief decision makers and highly influence maternal health. In Tanzania information is limited regarding influence of male involvement during ANC on utilisation of maternal health services.

Objectives To determine the effect of male involvement during ANC on use of maternal health services in Mwanza, Tanzania.

Design A cross-sectional study conducted from June to July 2019.

Setting This study was conducted at seven randomly selected health facilities providing reproductive, maternal and child health ( $\mathrm{RCH})$ services in Mwanza City.

Participants Included 430 postpartum women who delivered 1 year prior to the study and attending for $\mathrm{RCH}$ services (growth monitoring, vaccination, postpartum care).

Outcome measures 4 or more ANC visits, skilled birth attendant (SBA) use during childbirth and postnatal care (PNC) utilisation 48 hours after delivery.

Methods Interviews and observation of the women's ANC card were used to collect data. Data was entered, cleaned and analysed by SPSS.

Results The mean age of participants was 25.7 years. Of 430 women, $54.4 \%$ reported their partners attended ANC at least once, $69.7 \%$ reported they attended for four or more ANC visits during last pregnancy, 95\% used SBAs during childbirth and $9.2 \%$ attended PNC within 48 hours after delivery. Male involvement during ANC was significantly associated with four or more ANC visits (Crude Odds Ratio (COR): 1.90; 95\% Cl: 1.08-3.35) but not with SBA use or PNC utilisation.

Conclusion Male involvement in ANC is still low in Mwanza, as $46 \%$ of the partners had not attended with partners at ANC. Alternative strategies are needed to improve participation. Studies among men are required to explore the barriers of participation in overall RCH services.
Strengths and limitations of this study

The study had some strengths and limitations that have to be considered when interpreting the results.

- One of the strengths of this study was record review of women's antenatal care (ANC) card. This helped with the information on ANC care use; frequency and delivery and postnatal care information. We recruited women who were attending for postnatal care services and who delivered in past 1 year to assess the association of male participation and use of maternal health services. The coverage of vaccination service in Mwanza region is at $70 \%$. We might have therefore missed a proportion of those who do not bring children for vaccination and/or for growth monitoring and therefore overestimated the use of maternal health services.

- Men with partners who delivered in past 1 year in the community would have been a better population to answer questions of participation and challenges. Time and difficulty in getting them limited our ability to use this population.

Due to the cross-sectional nature of our study, we were unable to infer causal inferences.

\section{INTRODUCTION}

Male involvement in maternal, newborn and child health as well as other sexual and reproductive health programmes in Africa has been associated with improved maternal and child health outcomes. ${ }^{1}$ In many SubSaharan African countries where maternal and newborn deaths are high, women are not the main decision makers. Traditionally men are the heads of families and have a strong influence in decision making in matters pertaining to the use of women and children health services. ${ }^{2}$ Their participation as partners in antenatal care (ANC), delivery and child services has shown considerable benefits to women and children. ${ }^{3}$ 
Studies have shown an association between male involvement during pregnancy and positive uptake of reproductive and maternal health services as well as positive pregnancy outcomes. In family planning, male involvement improved uptake and continuation with the methods, ${ }^{4}$ while in prevention of mother-to-child HIV transmission programmes, male involvement during pregnancy is associated with increased HIV testing at ANC, uptake of prophylaxis to exposed child as well as increased adherence to infant-feeding options. ${ }^{5-7}$ Male support has also shown to decrease delay in seeking care when women have obstetric and newborn complications. ${ }^{6}$ Others have shown male involvement and support during pregnancy to increase counselling of danger signs and birth preparedness, increase frequency of ANC visits, use of health facility and skilled birth attendants (SBAs) during childbirth. ${ }^{89}$ UNICEF reports that when men are involved in pregnancy and given nutrition counselling, this can reduce the number of children born with low birth weight. ${ }^{9}$

Despite of its advantages, proportion of male involvement in ANC is low in low-income and middle-income countries including Tanzania where maternal and newborn deaths are high. ${ }^{10}{ }^{11}$ In Tanzania, few studies that evaluated male involvement in ANC show it was still low, ranging from $34.6 \%$ to $63 \% .{ }^{112}$ Different strategies to improve male participation have been implemented such as first track services to pregnant women who attended with their partners as shown in southern Tanzania and in other places opening services after work hours or in the weekends to accommodate men's busy schedules. Some of the interventions showed positive outcomes while others the opposite effect. ${ }^{10}$

In Tanzania, while $96 \%$ of pregnant women attend at least one for ANC, only $51 \%$ attend the recommended four or more ANC visits, $64 \%$ use SBAs during childbirth and $34 \%$ attend for postnatal care (PNC) within 48 hours after birth. ${ }^{12}$ The national targets are set for $90 \%$ women to reach the recommended four or more ANC visits and $80 \%$ deliver with SBAs by $2020 .^{12}$ WHO now recommends that a pregnant woman without complication should have at least eight contacts with the healthcare system and that first contact occurs before 12 weeks. ${ }^{13}$ The Tanzanian Lake zone (Mwanza region) where the study was conducted has poor maternal and newborn health indicators compared with national level where: $47.6 \%$ of pregnant women attend for four or more ANC visits, 53.3\% use skilled birth attendants during childbirth and $20.7 \%$ use PNC with 48 hours, respectively; while that of national level is $50.7 \%, 64 \%, 34.1 \%$, respectively. ${ }^{12}$

As stated in other settings, studies have shown an association between male involvement during ANC with increased ANC frequency, use of SBAs during childbirth and PNC utilisation. ${ }^{7}$ In Tanzania, there is limited information on the association of male involvement during ANC on the utilisation of reproductive health services along the continuum of care. This study aimed to assess the association of male involvement during ANC on frequency of ANC visits (attend four or more visits), use of SBAs during childbirth and PNC utilisation within 48 hours after delivery. SBA use during childbirth and immediate postpartum period is assessed because it is a key period in reducing maternal and newborn deaths. ${ }^{14}$

\section{METHODS}

\section{Study design and setting}

This was a cross-sectional study conducted in Mwanza City Council, Tanzania from June to July 2019. Mwanza City Council is one of the seven districts of Mwanza region in the Lake zone. The district is bordered to the south by Misungwi District, North by Ilemela District, west by Mwanza Bay of Lake Victoria, east by Magu District. The population of Mwanza region was approximately 2.8 million and of Mwanza City Council was 363452 according to the 2012 Census. The major economic activities in Mwanza City Council are business and fishing.

Mwanza City Council has a total of 63 health facilities: 11 hospitals, 12 health centres and 40 dispensaries. Of the 63 facilities, 46 ( 8 hospitals, 10 health centres and 28 dispensaries) offer reproductive and child health (RCH) services.

In Mwanza region the use of maternal and child health services is low compared with that of national level according to Tanzania Demographic and Health Survey (TDHS) (2015-2016) that is; four or more ANC visits is at $47.6 \%$, use of SBAs during delivery at $54 \%$, PNC within 2 days after delivery for women is at $20.7 \%$, vaccination coverage for children at $70 \%$ and modern contraceptive use at $18 \%$; while that of national level is $51 \%, 64 \%$, $34.1 \%, 75 \%$ and $32 \%$, respectively. ${ }^{12}$

\section{Study population}

The study included consenting postpartum women who had delivered within 1 year prior to the study and were attending the selected health facilities for routine $\mathrm{RCH}$ services. The RCH services included women bringing children for growth monitoring and children for vaccinations. Recruitment was conducted beyond the postpartum visit of 48 hours in order to ensure the generalisability of findings and avoid potential bias.

While attendance for PNC within 48 hours is a challenge in Tanzania, majority of women attend the facilities for vaccination and growth monitoring of their children. PNC care attendance at 6 weeks that coincides with the first vaccination is very high in Tanzania (99\%). This was done in order to ensure the study sample fairly represents the population of women of reproductive age at Mwanza City. Women who were not residents of Mwanza City Council were excluded from the study.

\section{Sample size and sampling}

The formula for precision was used for sample size calculation.

$$
N=\frac{Z^{2} p(1-p)}{E^{2}}
$$


Where: $\mathrm{N}=$ estimated sample size; $\mathrm{Z}=$ standard normal deviation corresponding to $5 \%$ level of estimated significance, which is $1.96 ; \mathrm{p}=53.3 \%$ as the prevalence of SBA utilisation during delivery in Mwanza City. ${ }^{12}$

Substituting the numbers in the formula, the minimum sample size was 382 . Adding $10 \%$ for non-response, the minimum sample size required for the study was 420 women.

Each level of health facility was sampled purposively based on the large number of attendees. One hospital (Nyamagana), two health centres (Makongoro and Igoma) and four dispensaries (Buhongwa, Mkoalani, Tambuka reli and Mahina) were selected to participate. At the health facility level, women meeting the inclusion criteria during the study period were invited to participate.

\section{Data collection methods, tools and procedures}

Data collection was conducted by four trained medical students over a period of 4 weeks. On average, each researcher was interviewing five women per day. The duration of the interview lasted from 35 to $40 \mathrm{~min}$ to complete. The researchers were from Kilimanjaro Christian Medical University College and they were not involved in offering routine care at facilities in Mwanza City. Face-to-face interviews were done to collect information from the participants. We opted for face-to-face interviews instead of self-filling because most women have low literacy level and prefer this method of data collection as documented also by TDHS. Record review of women's ANC card was done to get the exact number of ANC visits the women attended and delivery information if delivered at health facility.

Questionnaire was the tool used for data collection. It had both closed and opened ended questions. The questionnaire had five sections. The first part of the questionnaire collected sociodemographic and economic information. The second part collected information on reproductive characteristics as well as information on ANC attendance, frequency of ANC attendance and use of skilled providers during childbirth. The third part collected information on male involvement during ANC, at what gestation age, frequency they attended together and if they were HIV-couple counselled. The fourth part assessed the use of services after deliveries, PNC attendance and the last part assessed challenges women face when inviting partners to attend RCH care with them.

\section{Data analysis}

Data was entered and cleaned using SPSS V.20. Categorical variables were summarised using frequency and percentages while the continuous variables were summarised using measures of central tendency with their respective measures of dispersion.

The association between male involvement and each of outcome variables (four or more ANC visits, SBA use and PNC use) was assessed by using ORs with their respective 95\% CIs. Logistic regression analysis was used to control confounders. All associations were considered statistically significant at $\mathrm{p}<0.05$.

\section{Explanation and categorisation of variables}

The primary predictor of interest in this study was male involvement in ANC. In this study male participation was defined by attendance to ANC of the male partner for two or more times. This arose because during designing of the study and pretesting, it was found that women are expected to bring their partners for HIV-testing during pregnancy $^{11}{ }^{15}$ and therefore, participation was defined beyond the expected one visit. Therefore, male participation was assessed by asking women if they were accompanied by their partners to ANC and frequency. Those who attended for at least two visits or more and received services together during their last pregnancy (coded 1) and those who attended ANC with their partners less than two visits as well as those who did not attend ANC with their partners at all (coded 0).

There were three main outcome variables for this study namely: use of four or more ANC visits; SBA use during childbirth and PNC utilisation within 48 hours after delivery.

Attendance of four or more ANC visits was recorded by asking the number of visits a woman attended during pregnancy and verified from RCH card 1 . This variable was categorised at 0 (less than four ANC visits) and 1 (four or more ANC visits). SBA use was categorised as 1 (Yes) if a woman reported she was assisted by trained personnel and 0 (No) if she reported to have delivered at home and/or not assisted by trained personnel. PNC use categorised as 1 (Yes) if a woman was attended by skilled health personnel within 48 hours after birth and 0 (No) if she was not attended by skilled health personnel within 48 hours after birth.

\section{Patient and public involvement}

Patients or the public were not involved in the design, or conduct, or reporting, or dissemination plans of our research.

\section{RESULTS}

\section{Background characteristics of the participants}

A total of 430 participants were enrolled in the study. Out of 430 enrolled participants, $423(98.3 \%)$ attended for ANC in their last pregnancy and these are the ones included in the analysis of male participation during antenatal period.

The mean age of the 423 women was 25.7 years (SD 5.7). Most of the 423 participants, $83.9 \%$ were married or cohabiting, $58.4 \%$ had primary education, $90.8 \%$ were not formally employed and $68.3 \%$ had a minimum income of 45000 Tanzanian Shillings or less ( US\$20) per month. Table 1 shows other sociodemographic characteristics of the participants.

\section{Reproductive and obstetric characteristics}

Reproductive characteristics of the participants are presented in table 2. Of the 423 participants, $69.7 \%$ 
Table 1 Sociodemographic characteristics of the participants $(\mathrm{N}=423)$

\begin{tabular}{lrr}
\hline Variables & $\mathbf{N}$ & \multicolumn{1}{c}{$\%$} \\
\hline Age (years) & & \\
$<18$ & 3 & 0.7 \\
$18-24$ & 210 & 49.7 \\
$25-34$ & 171 & 40.4 \\
$35-49$ & 39 & 9.2
\end{tabular}

Highest level of education

\begin{tabular}{|lrr|}
\hline No formal education & 25 & 5.9 \\
\hline Primary education & 247 & 58.4 \\
\hline Secondary education & 127 & 30.0 \\
\hline Higher education & 24 & 5.7 \\
\hline Marital status & & \\
\hline Married/cohabiting & 355 & 83.9 \\
\hline Single & 56 & 13.3 \\
\hline Divorced/separated/widowed & 12 & 2.8 \\
\hline Formal employment & & \\
\hline No & 384 & 90.8 \\
\hline Yes & 39 & 9.2 \\
\hline
\end{tabular}

Source of income ( $\mathrm{N}=384)$

\begin{tabular}{|c|c|c|}
\hline Farmer & 21 & 5.5 \\
\hline Peasants & 34 & 8.9 \\
\hline Business & 123 & 32.0 \\
\hline Other* & 206 & 53.6 \\
\hline \multicolumn{3}{|c|}{ Average income per month (TZS) } \\
\hline$<46000$ & 289 & 68.3 \\
\hline $46000-99999$ & 61 & 14.4 \\
\hline $100000-200000$ & 39 & 9.2 \\
\hline$>200000$ & 34 & 8.1 \\
\hline \multicolumn{3}{|l|}{ Polygamous relationship } \\
\hline No & 401 & 94.8 \\
\hline Yes & 22 & 5.2 \\
\hline \multicolumn{3}{|c|}{ Partner's age (years) $(\mathrm{N}=355)$} \\
\hline $18-24$ & 47 & 13.2 \\
\hline $25-34$ & 186 & 52.4 \\
\hline$>35$ & 122 & 34.4 \\
\hline \multicolumn{3}{|c|}{ Partners education level $(\mathrm{N}=355)$} \\
\hline Primary education & 163 & 45.9 \\
\hline Secondary education & 154 & 43.4 \\
\hline Higher education & 38 & 10.7 \\
\hline
\end{tabular}

US\$=2280 Tanzanian Shillings (TZS) during data collection. *Other sources of income include shop keeping, food handling.

attended ANC for four or more times, but only 39.5\% started ANC during the first trimester of pregnancy. Majority of the participants (95\%) used SBAs during childbirth and $30.1 \%$ attended for PNC within 40 days
Table 2 Reproductive and obstetric characteristics of the study participants $(\mathrm{N}=423)$

\begin{tabular}{|c|c|c|}
\hline Variables & $\mathbf{N}$ & $\%$ \\
\hline \multicolumn{3}{|c|}{ Number of living children } \\
\hline 1 & 171 & 40.4 \\
\hline 2 & 114 & 27.0 \\
\hline$\geq 3$ & 138 & 32.6 \\
\hline
\end{tabular}

Gestational age in weeks at first visit during last pregnancy

$\begin{array}{lrr}\leq 12 & 167 & 39.5 \\ 13-27 & 234 & 55.3 \\ 28+ & 22 & 5.2 \\ \begin{array}{l}\text { Number of ANC visits } \\ <4\end{array} & 128 & 30.3 \\ 4+ & 295 & 69.7\end{array}$

Place of delivery (last pregnancy)

\begin{tabular}{lrr} 
Home & 7 & 5.0 \\
$\quad$ Health facility & 133 & 95.0 \\
Person assisted during delivery & & \\
$\quad$ Skilled birth attendant & 402 & 95.0 \\
$\quad$ Tradition birth attendant & 4 & 1.0 \\
$\quad$ Others (specify) & 17 & 4.0 \\
Mode of delivery & & \\
$\quad$ By SVD & 380 & 89.8 \\
$\quad$ By caesarean section & 43 & 10.2 \\
Time discharged after delivery (hours) & & \\
$\quad<6$ & 9 & 2.2 \\
$\quad 7-24$ & 314 & 77.2 \\
\hline $25-48$ & 27 & 6.6 \\
$\quad>48$ & 57 & 14.0 \\
Attendance for PNC (N=366) & & \\
$\quad$ No & 256 & 69.9 \\
$\quad$ Yes & 110 & 30.1 \\
\hline Time for first PNC after delivery (N=110) & & \\
$\quad$ Within 2 days & 10 & 9.2 \\
$\quad$ After 2 days & 99 & 90.8 \\
\hline
\end{tabular}

ANC, antenatal care; PNC, postnatal care; SVD, spontaneous vaginal delivery.

after delivery. Of the 110 women who attended for PNC, only $9.2 \%$ did so within 48 hours after delivery.

\section{Proportion of male involvement during ANC}

Table 3 shows the proportion of male involvement during ANC. Of the 423 women, 54\% (230) reported that their partners attended ANC with them at least once. Of the 230 women whose partners attended, 142 (61.7\%) attended once; while $52(22.6 \%)$ attended for two times and $36(8.3 \%)$ attended for three or more times. Majority 


\begin{tabular}{|c|c|c|}
\hline Variables & $\mathbf{N}$ & $\%$ \\
\hline \multicolumn{3}{|c|}{ Accompanied by partner during ANC } \\
\hline No & 193 & 45.6 \\
\hline Yes & 230 & 54.4 \\
\hline \multicolumn{3}{|c|}{ Frequency of ANC visit with partner } \\
\hline None & 193 & 45.6 \\
\hline 1 & 142 & 33.6 \\
\hline 2 & 52 & 12.3 \\
\hline $3+$ & 36 & 8.5 \\
\hline \multicolumn{3}{|c|}{ ANC visit accompanied by partner $(\mathrm{N}=230)$} \\
\hline First & 221 & 96.1 \\
\hline Second & 4 & 1.7 \\
\hline Third or more & 5 & 2.2 \\
\hline \multicolumn{3}{|c|}{ Gestational age accompanied by partner $(\mathrm{N}=230)$} \\
\hline 1st trimester & 103 & 44.8 \\
\hline 2nd trimester & 112 & 48.7 \\
\hline 3rd trimester & 15 & 6.5 \\
\hline \multicolumn{3}{|c|}{ Received health education together with partner $(\mathrm{N}=230)$} \\
\hline No & 3 & 1.3 \\
\hline Yes & 227 & 98.7 \\
\hline \multicolumn{3}{|c|}{ Tested for HIV during ANC (N=230) } \\
\hline No & 5 & 2.2 \\
\hline Yes & 225 & 97.8 \\
\hline
\end{tabular}

of the 230 partners $(96 \%)$ attended ANC with the women at their first visit and were tested for HIV (97.8\%).

\section{Association between male involvement in ANC and use of reproductive and maternal health services}

Women who attended for ANC with partners had significantly higher frequency of attending for four or more ANC visits than others $(79.5 \%$ vs $67.2 \%$; $\mathrm{p}=0.024)$. They did not have higher SBA use during childbirth $194.3 \%$ vs $95.2 \%$; $\mathrm{p}=0.728$ ) or higher attendance for $\mathrm{PNC}$ within 48 hours after delivery $(3.4 \%$ vs $2.1 \%$; $\mathrm{p}=0.468)$. The prevalence of ANC attendance, SBA use and PNC utilisation by other sociodemographic characteristics are presented in table 4.

Table 5 presents the results of logistic regression analysis of the association between male involvement during ANC and four or more ANC visits, SBA use during delivery and PNC utilisation within 48 hours taking into account other variables. In the crude analysis, women who were accompanied with their partner to ANC had 1.9 times higher odds of attending four or more ANC visits compared with women who were not accompanied with their partners to ANC. After adjusting for other variables, women who were accompanied with their partner had 1.7 times higher odds of attending four or more ANC visits compared with those who were not. This association, however, was not statistically significant. Age, level of education, employment status and polygamous relationship had no association with attending four or more ANC visits.

During crude and adjusted analysis, male participation during ANC was not associated with SBA use during childbirth. In adjusted analysis, formal education was the only factor significantly associated with SBA use during childbirth $(p=0.013)$. Male involvement during ANC, age, marital status, level of education, employment status, polygamous relationship and number of children of the participants had no association with PNC use within 48 hours after delivery.

\section{DISCUSSION}

The results of this study show that nearly half $(45.6 \%)$ of the men do not participate in the antenatal care with their partners. It was also noted $70 \%$ of the women attended four or more ANC visits in their last pregnancy, 95\% used SBAs during childbirth and 9\% had PNC utilisation within 48 hours after delivery. Male involvement in ANC was associated with attendance for four or more ANC visits but not with SBA use during childbirth orPNC utilisation within 48 hours after delivery.

From this study, male involvement in ANC was significantly associated with attendance of four or more ANC visits. This finding was similar to those reported in Ethiopia and Nepal where women who received ANC education with their partners were more likely to attend four or more ANC visits than those who did not. ${ }^{89}$ This result could possibly be explained by the fact that almost all women who went with their partners $(96 \%)$ received health education together with their partners. Based on these findings it implies that educating husbands/male partners about the importance of healthcare for the family could potentially increase the promotion of some health-seeking behaviour such as ANC.

In the present study we found no significant association between male involvement and SBA use during childbirth. Our finding was in contrast to previous studies from India and Zambia which reported that when pregnant women are accompanied and received education together with their partners at ANC, they were more likely to deliver at health facilities. ${ }^{16}{ }^{17}$ This could be explained by the fact that the majority of women in our sample used SBAs $(95 \%)$ and implies that most women in Mwanza despite of the presence of their husband during ANC have knowledge on the importance of SBA utilisation during delivery.

This study showed that there was no association between male involvement and PNC utilisation within 48 hours after delivery. This finding was also different from other studies which were done in Nepal, Zambia and Burkina Faso which showed that women who received education with their partners were more likely to return for PNC compared with those who were not. ${ }^{8} 17$ This difference could be explained due to different timing of postnatal check-up assessment in Nepal which assessed PNC check-up after 1 week while in Zambia and Burkina Faso 


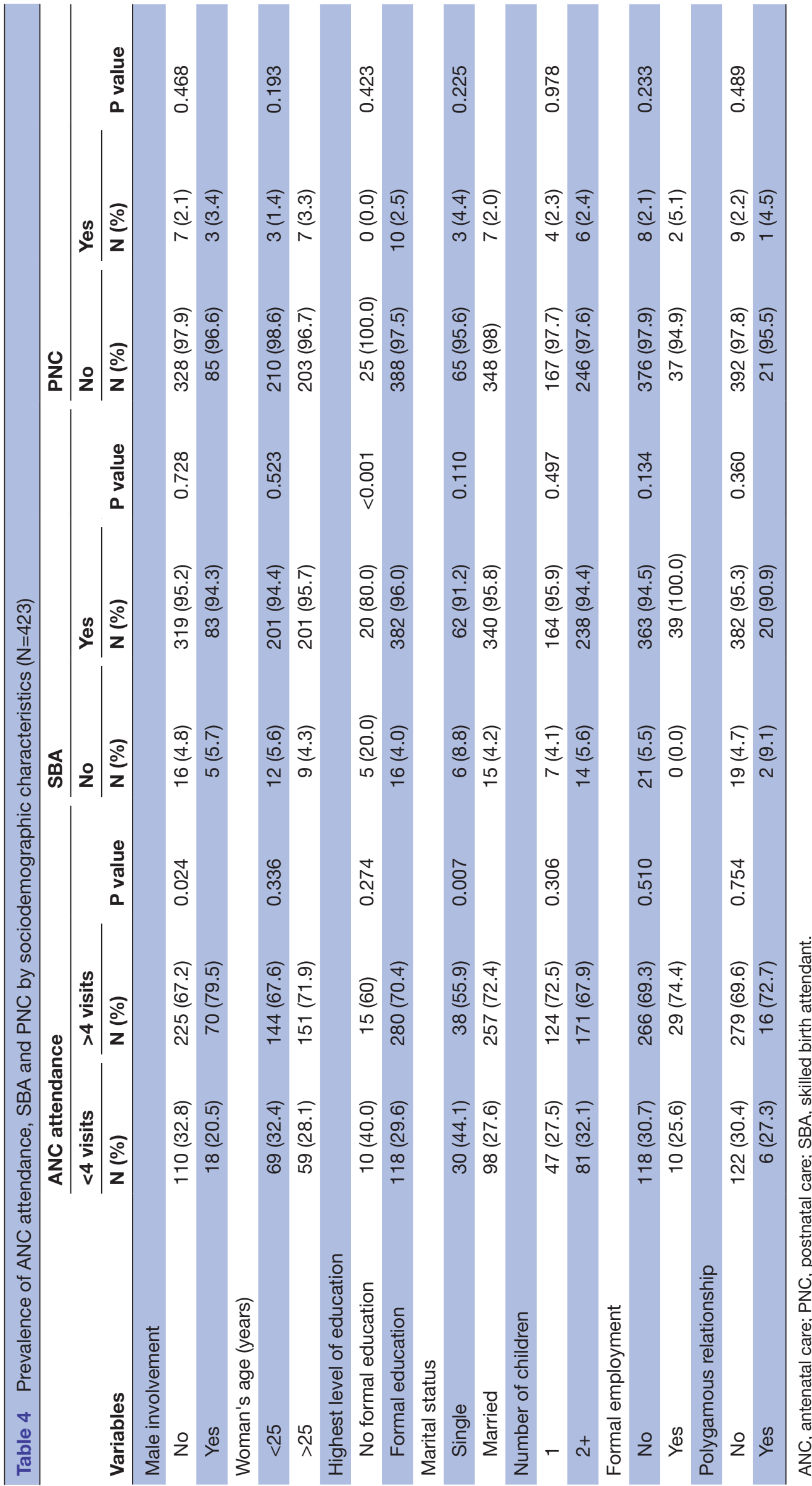




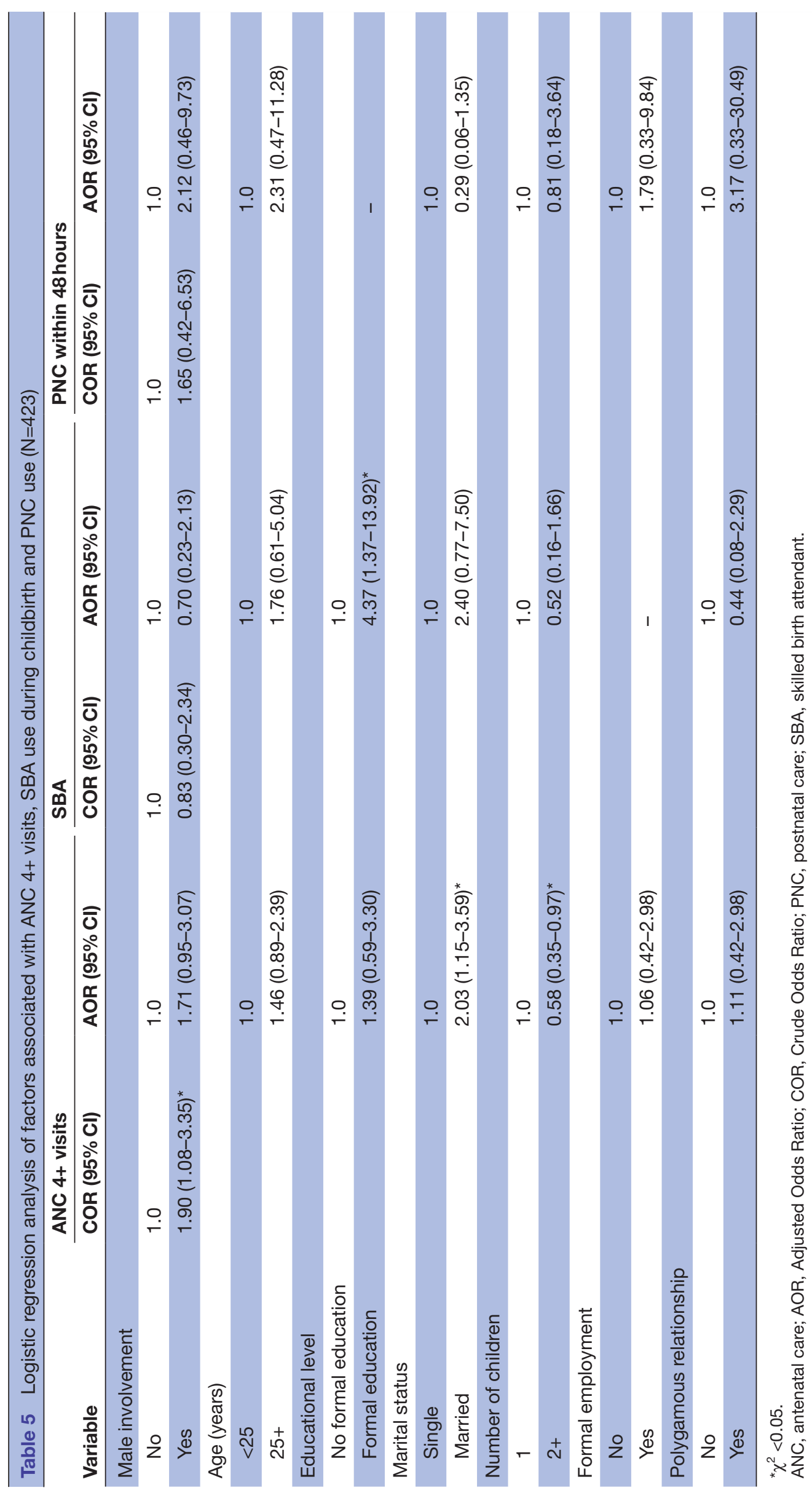


only PNC check-up was assessed regardless of time when the women returned. WHO recommends that all women and their neonates to have the first postnatal visit within 48 hours after delivery. Most of the interviewed women in Mwanza City regardless of their husbands' presence during ANC did not return for postnatal check-up (70\%), but rather returned after 6 weeks for child vaccination. There is a need to assess further if there are cultural practices that influence PNC attendance.

\section{CONCLUSION}

A substantial proportion of women $(46 \%)$ do not attend for ANC with their partners in Mwanza City. Most of those who attend $(61.7 \%)$, attend once. Male attendance influenced frequency of ANC attendance (four or more times) among women, but not SBA or PNC use.

There is a need to further understand specific barriers for male participation in this setting so that alternative strategies to reach male partners in maternal, newborn and child health services can be designed. Furthermore, there is a need for local health teams to assess low PNC use in general and within 48 hours at the setting as this is an important period to improve maternal and newborn survival.

\section{Author affiliations}

${ }^{1}$ Department of Epidemiology and Biostatistics, Kilimanjaro Christian Medical University College, Moshi, Tanzania

${ }^{2}$ Department of Epidemiology and Biostatistics, Institute of Public Health, Kilimanjaro Christian Medical University College, Moshi, Tanzania

${ }^{3}$ Office of City Medical Officer, Mwanza, Tanzania

${ }^{4}$ Department of Community Health, Institute of Public Health, Kilimanjaro Christian Medical University College, Moshi, Tanzania

Acknowledgements We would like to thank the city medical officer, district RCH coordinator, health facility in charge of Mwanza City Council for their help during the study period. We would also like to thank the women who participated in the study for their time and cooperation.

Contributors CCN, NG, FMS, BJL, JM, MY and SEM designed the study, interpreted the results and read for intellectual content. CCN, NG, FMS and MY participated in the data analysis. CCN, NG and FMS prepared the manuscript and all the other authors reviewed the manuscript before submission. All authors read and approved the final manuscript.

Funding BJL and SEM were THRiVE-2 faculty and were partially supported by the DELTAS Africa Initiative grant \# DEL-15-011 to THRiVE-2.

Competing interests None declared.

Patient and public involvement Patients and/or the public were not involved in the design, or conduct, or reporting, or dissemination plans of this research.

Patient consent for publication Not required.

Ethics approval Ethical approval to conduct the study was obtained from the Kilimanjaro Christian Medical University College Ethical Committee (Ethical approval number UG 001).Permission to carry out the study was obtained from Mwanza City Council Medical officer of health and in-charge of selected health facilities. Verbal consent was requested from each participant. Confidentiality with regards to the information of the participants was highly maintained as no names appeared in the questionnaires. Participants who did not want to participate were not denied access to services at the health facilities.
Provenance and peer review Not commissioned; externally peer reviewed.

Data availability statement Data are available upon reasonable request. Data and material will be available upon request from the corresponding author.

Open access This is an open access article distributed in accordance with the Creative Commons Attribution Non Commercial (CC BY-NC 4.0) license, which permits others to distribute, remix, adapt, build upon this work non-commercially, and license their derivative works on different terms, provided the original work is properly cited, appropriate credit is given, any changes made indicated, and the use is non-commercial. See: http://creativecommons.org/licenses/by-nc/4.0/.

\section{ORCID iDs}

Beatrice J Leyaro http://orcid.org/0000-0002-8525-0281

Mashavu H. Yussuf http://orcid.org/0000-0002-5080-2437

\section{REFERENCES}

1 Chibwae A, Kapesa A, Jahanpour OLA, et al. Attendance of male partners to different reproductive health services in Shinyanga District, North western Tanzania. Tanzan J Health Res 2018;20:1-11.

2 Yargawa J, Leonardi-Bee J, et al. Male involvement and maternal health outcomes: systematic review and meta-analysis. J Epidemiol Community Health 2015;69:604-12.

3 Tokhi M, Comrie-thomson L, Davis J, et al. Involving men to improve maternal and newborn health : A systematic review of the effectiveness of interventions 2018:1-16.

4 Farquhar C, Kiarie JN, Richardson BA, et al. Antenatal couple counseling increases uptake of interventions to prevent HIV-1 transmission. J Acquir Immune Defic Syndr 2004;37:1620-6.

5 Msuya SE, Mbizvo EM, Hussain A, et al. Low male partner participation in antenatal HIV counselling and testing in northern Tanzania: implications for preventive programs. AIDS Care 2008;20:700-9

6 Bhatta DN. Involvement of males in antenatal care, birth preparedness, exclusive breast feeding and immunizations for children in Kathmandu, Nepal. BMC Pregnancy Childbirth 2013;13:1.

7 Mullany BC, Becker S, Hindin MJ. The impact of including husbands in antenatal health education services on maternal health practices in urban Nepal : results from a randomized controlled trial 2007;22:166-76.

8 Forbes F, Wynter K, Wade C, et al. Male partner attendance at antenatal care and adherence to antenatal care guidelines: secondary analysis of 2011 Ethiopian demographic and health survey data. BMC Pregnancy Childbirth 2018;18:145.

9 UNICEF. The State of the World's Children 2009.

10 Peneza AK, Maluka SO. 'Unless you come with your partner you will be sent back home': strategies used to promote male involvement in antenatal care in Southern Tanzania. Glob Health Action 2018;11:1449724.

11 Vermeulen E, Solnes Miltenburg A, Barras J, et al. Opportunities for male involvement during pregnancy in Magu district, rural Tanzania. BMC Pregnancy Childbirth 2016;16:1-9.

12 MoHCDGEC, MoH, NBS, OCGS, ICF. Tanzania Demographic and Health Survey and Malaria Indicator Survey (TDHS-MIS) 2015-16 2016.

13 WHO. WHO Recommendations on Antenatal Care for a Positive Pregnancy Experience : Summary Highlights and Key Messages from the World Health Organization's 2016 Global Recommendations for Routine Antenatal Care 2018;10:1-10.

14 WHO. World Health Organization Maternal mortality fact sheet. World Heal Organ Genever, Swizerl 2015.

15 Chattopadhyay A. Men in maternal care : Evidence from India. J Biosoc Sci 2014;00:1-26.

16 Kashitala J, Nyambe N, Mwalo S, et al. Is Male Involvement in ANC and PMTCT Associated with Increased Facility-Based Obstetric Delivery in Pregnant Women ? Zambia has made great strides in implementing Methods Design and instruments. Afr J Reprod Health 2015;19:116-23.

17 Daniele MAS, Ganaba R, Sarrassat S, et al. Involving male partners in maternity care in Burkina Faso: a randomized controlled trial. Bull World Health Organ 2018;96:450-61. 